\title{
Ganoderma lucidum and professor Zhi-Bin Lin
}

\section{Ding-Feng Su' and Xiao-Ling $\mathrm{Zhu}^{\mathbf{2}}{ }^{*}$}

1 Department of Pharmacology, Second Military Medical University, Shanghai, China

2 Department of Pharmacology, School of Basic Medical Sciences, Peking University Health Science Center, Beijing, China

${ }^{*}$ Correspondence: xiaolingzhu88@yahoo.com.cn

Ganoderma is a genus of polypore mushrooms and includes about 80 species. Ganoderma is characterized by basidiocarps that are large, perennial, woody brackets, also called "conks." Ganoderma lucidum, also known as lingzhi, is the most commonly cultivated type of Ganoderma in China, and has been used for medical purposes for more than 2,000 years (Figure 1). Lingzhi is used in China for a great variety of purposes, including asthma, chronic obstructive pulmonary disease, sleep disorder, hepatitis, leucopenia, hypertension, hyperlipidemia, diabetes, and cancer. It is also widely used to promote health in those under a "sub-health" status (Lin, 2011).

Studies of lingzhi using modern technologies started in 1970s. Up to March 2012, 4,326 and 979 research papers have been deposited into the Chinese CNKI and the Pubmed databases, using "lingzhi" and "Ganoderma" as search terms respectively.

Professor Zhi-Bin Lin is the leading pioneer in the research of lingzhi in the modern era (Figure 2). Interestingly, his name, in Chinese pronunciation, means as a soldier for lingzhi. Much of Professor Lin's career was devoted to the research of lingzhi. He systematically studied the pharmacological actions of lingzhi, and identified a number of active ingredients responsible for the immune modulatory, anti-cancer, anti-diabetic, and anti-oxidant properties of lingzhi. He and his colleagues also developed a series of pharmaceutical/nutraceutical products. His achieve- ments represent an exemplary in developing herbal medications. Inspired by the results from the study of lingzhi, Professor Lin extended his research into many other medicinal herbs, including Tremella fuciformis, Wolfiporia extensa, and Lentinula edodes, and made many discoveries (Lin, 2011).

Professor Lin was a visiting scholar at University of Illinois at Chicago, USA, Honorary Professor at the Perm Pharmaceutical Research Institute, Russia, Adjunct Professor at more than 10 Chinese University including Nankai University and Hongkong University. He was a member of the Chinese Pharmacopeia Committee, the Executive Committee at the International Union of Basic and Clinical Pharmacology (IUPHAR) and Southeast Asian Western Pacific Regional Federation of Pharmacologists (SEAWP-RFP), ex-President of the Chinese Pharmacological Society (CNPHARS), ex-President of the Standing Committee of Apitherapy at the International Federation of Beekeepers' Associations (APIMONDIA).

During the past 10 years, Professor Lin has been focusing his efforts in modernizing the use of lingzhi. He set up a cultivation base, and standardized the pharmaceutical processes, including extraction and purification of the active components of lingzhi, and developed a set of criteria for quality control and assurance. Last but not least, Professor Lin is a great educator and a pioneer in disseminating scientific findings to the general public.

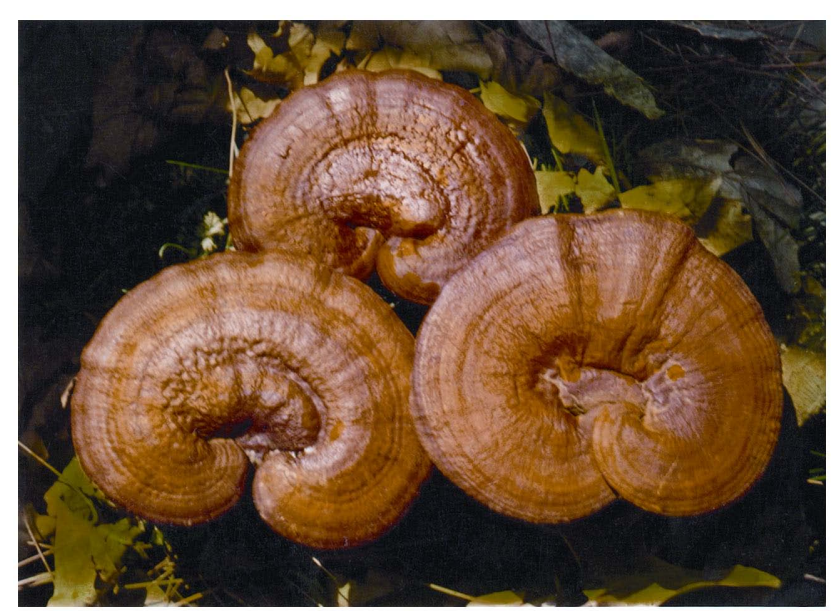

FIGURE 1 | Ganoderma lucidum (Leyss. ex Fr.) Karst.

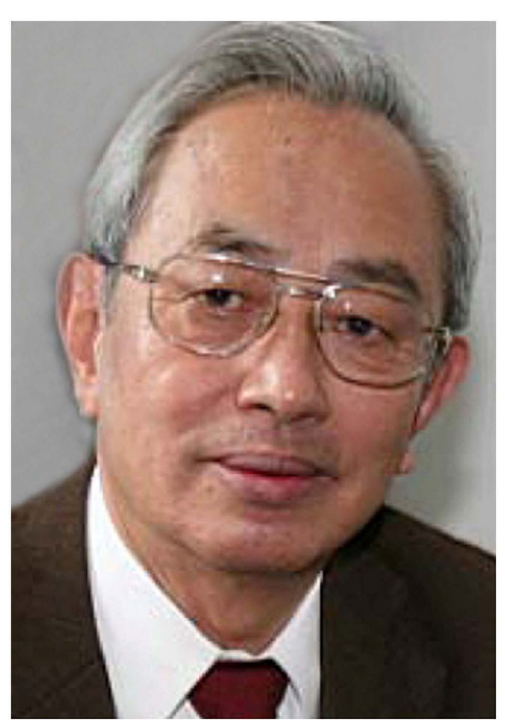

FIGURE 2 | Professor Zhi-Bin Lin. 


\section{REFERENCE}

Lin, Z. B. (2011). Paper collection of Professor Zhi-Bin Lin Engaged in Medical Education and Scientific Research Work at the 50th Anniversary (1961-2011). Beijing: Peking University Medical Press.
Received: 05 March 2012; accepted: 08 March 2012; published online: 28 March 2012.

Citation: Su D-F and Zhu X-L (2012) Ganoderma lucidum and professor Zhi-Bin Lin. Front. Pharmacol. 3:51. doi: 10.3389/ fphar.2012.00051
This article was submitted to Frontiers in Ethnopharmacology, a specialty of Frontiers in Pharmacology.

Copyright (C) 2012 Su and Zhu. This is an open-access article distributed under the terms of the Creative Commons Attribution Non Commercial License, which permits non-commercial use, distribution, and reproduction in other forums, provided the original authors and source are credited. 